\title{
Optimization of the Loading Process of Artemisia absinthium Volatile Oil in a Mesoporous Material as Drug Delivery System
}

\author{
Bogdan Purcareanu ${ }^{1,2} \mathbb{( D}$, Adelina Bicu ${ }^{1, *(\mathbb{D})}$, Mihai-Alexandru Florea $\left.{ }^{1} \mathbb{(}\right)$, Veronica Drumea ${ }^{(\mathbb{D})}$, Dan \\ Eduard Mihaiescu ${ }^{2}$ (D), Laura Olariu 1,3 (D) \\ 1 Biotehnos SA, Gorunului Street No. 3-5, 075100 Otopeni, Ilfov, Romania; bogdan.purcareanu@ biotehnos.com (B.P.); \\ adelina.bicu@biotehnos.com (A.B.); alexandru.florea@biotehnos.com (M.A.F.); veronica.drumea@biotehnos.com \\ (V.D.); lolariu@biotehnos.com (L.O.); \\ 2 University Politehnica of Bucharest, Faculty of Applied Chemistry and Materials Science, Polizu Street No. 1-7,011061 \\ Bucharest, Romania; bogdan.purcareanu@biotehnos.com (B.P.); danedmih@gmail.com (D.E.M.); \\ 3 The Academy of Romanian Scientists, No. 54 Spl. Independentei, 050094, Bucharest, Romania \\ * Correspondence: adelina.bicu@ biotehnos.com; adelina.bicu@gmail.com;
}

Received: 15.03.2021; Revised: 10.04.2021; Accepted: 14.04.2021; Published: 20.04.2021

\begin{abstract}
The study aimed to use a mesoporous material as a drug delivery system, loaded in different ways with volatile oil extracted from Artemisia absinthium, to evaluate the most effective loading method. A specific design of the mesoporous material was obtained through template/silica source ratio optimization in the synthesis process. Further bioactive compounds from the volatile oil were loaded in the mesopores. The obtained composite material has the potential to be used as low release drug carrier with anthelmintic activity. FT-IR analysis was used to prove the template removal due to the postsynthesis washing steps and the loading efficiency. The final loaded materials were analyzed qualitatively (percentage from the profile of some identified components, with about $90 \%$ recovery) and quantitatively (eucalyptol, linalool, $\beta$-myrcene, o-cymene, and $\alpha, \beta$ thujone). Eight different loading methods were compared in this study, and a high correlation factor $\left(\mathrm{R}^{2}>0.73\right)$ was obtained through ANOVA statistical data processing related to the $2-5^{\circ} \mathrm{C}$ experiment.
\end{abstract}

Keywords: mesoporous materials; Artemisia absinthium volatile oil; loading process; GC-MS analysis; drug delivery.

(C) 2021 by the authors. This article is an open-access article distributed under the terms and conditions of the Creative Commons Attribution (CC BY) license (https://creativecommons.org/licenses/by/4.0/).

\section{Introduction}

Due to their specific morphology and characteristics, mesoporous materials are intensively studied as carriers for many types of substances, including volatile oils. These materials have the capacity to entrap, based on their porosity and surface charge, and to encapsulate volatile components, ensuring protection against volatilization and improvement of their efficacy [1-3]. Volatile oils have many therapeutical properties, being used as antibacterial, antiviral agents, antioxidants, as skin penetration enhancers for transdermal drug delivery, even in cancer therapy [4-6]. Artemisia absinthium (wormwood) is an important therapeutical plant with significant pharmacological activities, such as antiviral, antimicrobial, hepatoprotective, and wound healing anti-inflammatory, antioxidant, antifungal, anthelmintic, etc. [7-9]. Special attention is given to the anthelmintic activity due to the hepatic toxicity of the pharmaceutical active substances used commonly in treating worm infections [10]. There 
have been made numerous tests to prove the effectiveness of wormwood extracts, including the essential oil. Used on mice infected with Trichinella spiralis larvae, after 7 days of oral administration, the essential oil at $1 \mathrm{mg} / \mathrm{mL}$ showed larvicidal effectiveness up to 99,99\% [11]. Oral administration of essential oils can be challenging because of the possible changes through the gastrointestinal tract related to effective concentration drop or chemical modifications (small intestine and colon) [12]. In this regard, mesoporous materials are feasible options related to their low release capabilities and protective effect, combined with volatile oils' efficacity, including volatile wormwood oil [13].

One of the greatest challenges in this study was related to the mesoporous material's loading process with a proper amount of volatile wormwood oil, considering that most components are slightly volatile and require mild conditions in the loading process. The most common loading techniques found in the literature are represented by two main categories: 1) loading the bioactive compounds using methods without organic solvents like physical mixing, co-milling, melt method, microwave irradiation; 2) by using organic solvents to encapsulate the bioactive compounds through phenomena like adsorption, incipient wetness impregnation, solvent evaporation, supercritical and liquid $\mathrm{CO}_{2}$ technology, one-pot drug loading and synthesis and chaperone assistance. Some loading techniques are time and money-consuming, while other loading methods' efficiency is significantly affected by the loading capacity and physicochemical properties of the support or by the specific target/support interactions in the loading process. From this perspective, co-milling, solvent evaporation, vapor adsorption, and nitrogen flux adsorption methods can be considered potential techniques for volatile oil loading [14-16].

In the present study, after the mesoporous support synthesis and the essential oil extraction process (neo-Clevenger, hydrodistillation), 8 different loading strategies were compared to optimize the essential oil loading process in the mesoporous matrix. After a qualitative and quantitative approach, an ANOVA statistical evaluation of the obtained data was performed to highlight the best loading method.

\section{Materials and Methods}

\subsection{Reagents and chemicals.}

High purity reagents were used: Ethanol absolute, puriss p.a., Acetic acid puriss $(99,8-$ $100,5 \%)$ and Ammonium hydroxide solution puriss p.a. ( 25\% $\mathrm{NH}_{3}$ basis) were purchased from Honeywell, Sodium hydroxide pellets from Bernd Kraft, Sodium trisilicate $(\geq 18 \% \mathrm{Na}$ basis and $\geq 60 \%$ Si basis) from Sigma-Aldrich, Linalool from Dr. Ehrenstorfer; p-Cymene from Chromadex; isomers $\alpha+\beta$ Thujone, Myrcene, and Eucalyptol from Sigma-Aldrich,_each of them with the certified value of purity, Ethyl acetate from Carlo Erba, Stearic acid from Sigma-Aldrich. During the entire study, water was obtained from the Milli-Q equipment.

\subsection{Extraction of volatile oil from Artemisia absinthium.}

A neo-Clevenger-type hydrodistillation device was used to extract the volatile oil from wormwood (a dried herb with flowers). $300 \mathrm{~g}$ of vegetable material was introduced into 2000 $\mathrm{mL}$ of water and processed for about 3 hours. The final product was dried and analyzed by GCMS. 


\subsection{Synthesis of mesoporous material.}

For the mesoporous material synthesis, sodium trisilicate was used as a silica source and stearic acid as a template, in a mildly acidic medium, at room temperature. The silica solution was homogenized under stirring with the template ethanolic solution and precipitated with an acidic solution of acetic acid in the presence of ammonium hydroxide as catalyst. To eliminate the organic components and other residues from the synthesized material, several washing steps with ultrapure water $\left(\right.$ at $70^{\circ} \mathrm{C}$ ) were performed. The final drying process was performed at $50^{\circ} \mathrm{C}$, under vacuum (50 mbar), for 12 hours.

\subsection{Loading techniques of the mesoporous materials with Artemisia absinthium volatile oil.}

To achieve a higher yield of loading for Artemisia absinthium volatile oil in the obtained mesoporous material, eight types of loading techniques were approached. The first one was conducted by a gradient concentration method using a rotary evaporator at $30-35{ }^{\circ} \mathrm{C}$, under a high vacuum. The second one consisted of a loading process based on vapor adsorption by mixing the volatile wormwood oil with mesoporous material, in a tightly closed vial, under stirring, at $50^{\circ} \mathrm{C}$, for 24 hours. The loaded material was obtained by centrifugation and drying in nitrogen flow. The next two methods used nitrogen flow, at low temperature $\left(2-5^{\circ} \mathrm{C}\right)$, one under vacuum and another without vacuum. The same method, in nitrogen flow, at low temperature $\left(2-5^{\circ} \mathrm{C}\right)$, without vacuum, was applied using methanol instead of ethanol because it has a lower boiling point, thus the evaporation process of the solvent being faster. The last method was manual homogenization with an agate mortar at low temperature $\left(2-5^{\circ} \mathrm{C}\right)$. The mesoporous material was mixed with volatile wormwood oil for 5 minutes. For the process control and to estimate the loading capacity and the molecule competition for the particle pores, the material was loaded with two solutions of $\alpha, \beta$-thujone, at different concentrations, one with the concentration level quantified from the volatile oil and the second one with a much higher concentration. The loading process chosen for $\alpha, \beta$ - thujone standard was under nitrogen flow, at low temperature $\left(2-5^{\circ} \mathrm{C}\right)$, without vacuum. All the loaded materials were milled and stored at low temperature $\left(2-8^{\circ} \mathrm{C}\right)$ before the GC-MS analysis. The parameters of the eight loading methods are summarized in Table 1.

Table 1. The parameters for loading techniques applied for volatile wormwood oil.

\begin{tabular}{c|c|c|c|c|c} 
Conditions & Solution & $\begin{array}{c}\text { Bath } \\
\text { temperature } \\
(\mathbf{C})\end{array}$ & $\begin{array}{c}\text { Vaccum } \\
(\mathbf{T o r r})\end{array}$ & $\begin{array}{c}\text { Flow } \mathbf{N}_{\mathbf{2}} \\
\mathbf{( P S I})\end{array}$ & $\begin{array}{c}\text { Magnetic stirrer / } \\
\text { rotation stirrer } \\
(\mathbf{r p m})\end{array}$ \\
\hline Method 1 & EtOH & 35 & 50 & - & 200 \\
\hline Method 2 & EtOH & 50 & - & 15 & 1400 \\
\hline Method 3 & EtOH & $2-5$ & - & 15 & 200 \\
\hline Method 4 & EtOH & $2-5$ & 500 & 15 & 200 \\
\hline Method 5 & wormwood oil & $2-5$ & - & - & manual milling \\
\hline Method 6 & $\alpha, \beta$ - thujone standard 1 & $2-5$ & - & 15 & 200 \\
\hline Method 7 & $\alpha, \beta$ - thujone standard 2 & $2-5$ & - & 15 & 200 \\
\hline Method 8 & MeOH & $2-5$ & - & 15 & 200
\end{tabular}

2.5. B.E.T. and B.J.H. characterization of mesoporous material.

Nitrogen adsorption / desorption isotherms were recorded at 77,35 $\mathrm{K}$ at relative pressure range $\mathrm{p} / \mathrm{p}_{0}=0,005-1,0$, using a Quantachrome NOVA 2200e Gas Sorption Analyzer. Data 
processing was performed using NovaWin software version 11.03. Before the adsorption measurements, the samples were degassed at $50^{\circ} \mathrm{C}$, in a vacuum, for 5 hours. Using the B.E.T. (Brunauer-Emmett-Teller) theory, the specific surface area, including surface irregularities and pore walls, of particles is determined at the atomic level by adsorption of an inert gas (nitrogen). The total pore volume was estimated from the adsorbed volume at a relative pressure $\mathrm{p} / \mathrm{p}_{0}$ close to unity. The pore size distribution and the mesopore volume were obtained from the isotherm desorption branch. Estimations of total pore volume and pore size distribution were made by applying the Barrett-Joyner-Halenda (B.J.H.) model.

\subsection{FT-IR characterization of the mesoporous material and loaded materials.}

FT-IR spectra were performed with a Perkin Elmer spectrometer. Using the diamond crystal attenuated total reflective (ATR) mode, 32 spectra were acquired for background and 64 spectra for each sample, at a resolution of $4 \mathrm{~cm}^{-1}$, on the spectral range $550-4000 \mathrm{~cm}^{1}$.

\subsection{Gas chromatography (GC-MS) analysis of loaded mesoporous materials.}

2.7.1. Preparation of standard solutions for volatile oil quantification.

Approximately $10 \mathrm{mg}$ of each individual compound were weighed in $10 \mathrm{~mL}$ graduated flasks and solubilized in ethyl-acetate. The obtained standard solutions were stirred and ultrasonicated for 1 minute. The stock calibration solution was prepared by mixing the accurately measured volumes of each solution and the calibration solutions by diluting the mixed solution in exact proportions with ethyl acetate.

\subsubsection{Chromatography analysis of volatile oil.}

Chromatographic profile of volatile oil and the quantification of several compounds of interest (linalool, cymene, myrcene, eucalyptol (cineol), $\alpha, \beta$ thujone) was obtained by using a gas chromatograph Thermo Scientific TRACE 1310 coupled with a triple quadrupole mass spectrometer (TSQ 8000 EVO). The analysis parameters were: column TG-5SilMS, $30 \mathrm{~m}, \varnothing$ $=0.25 \mathrm{~mm}$, film $=0.25 \mu \mathrm{m}, 5 \%$ phenyl methyl polysiloxane, flow rate $1.2 \mathrm{~mL} / \mathrm{min}$, inlet temperature $280^{\circ} \mathrm{C}$ in split mode $50: 1$, oven program starts from $90^{\circ} \mathrm{C}$ for $5 \mathrm{~min}$, then with $10^{\circ} \mathrm{C} / \mathrm{min} \rightarrow 280^{\circ} \mathrm{C}$, transfer line temperature $270^{\circ} \mathrm{C}$, source temperature $230^{\circ} \mathrm{C}$, the mass spectrometer was set to scan between 40-500 amu.

\subsection{Statistical analysis of the loading techniques' efficacy.}

The statistical analysis was performed with IBM SPSS Build 1.0.0.1447, 64-bit edition. Experimental data from six runs $(\mathrm{N} / \mathrm{run}=47, \mathrm{~N}$ total $=282)$ were analyzed using one-way ANOVA. In order to determine which specific group differed from each other, we applied post hoc tests (Tukey Test). Tukey Test uses the "Honest Significant Difference," a number representing the distance between groups, to compare every mean with every other mean.

\section{Results and Discussion}

\subsection{B.E.T. and B.J.H. characterization of mesoporous material.}

From the B.E.T. results, it was highlighted that the synthesized material has a specific surface area of $536,9 \mathrm{~m}^{2} / \mathrm{g}$, and from the B.J.H. model, a total pore volume of $0,318 \mathrm{~cm}^{3} / \mathrm{g}$ 
and a pore diameter of 2,37 $\mathrm{nm}$ were obtained. The obtained adsorption-desorption isotherm is a type IV, specific for mesoporous materials (Figure 1).

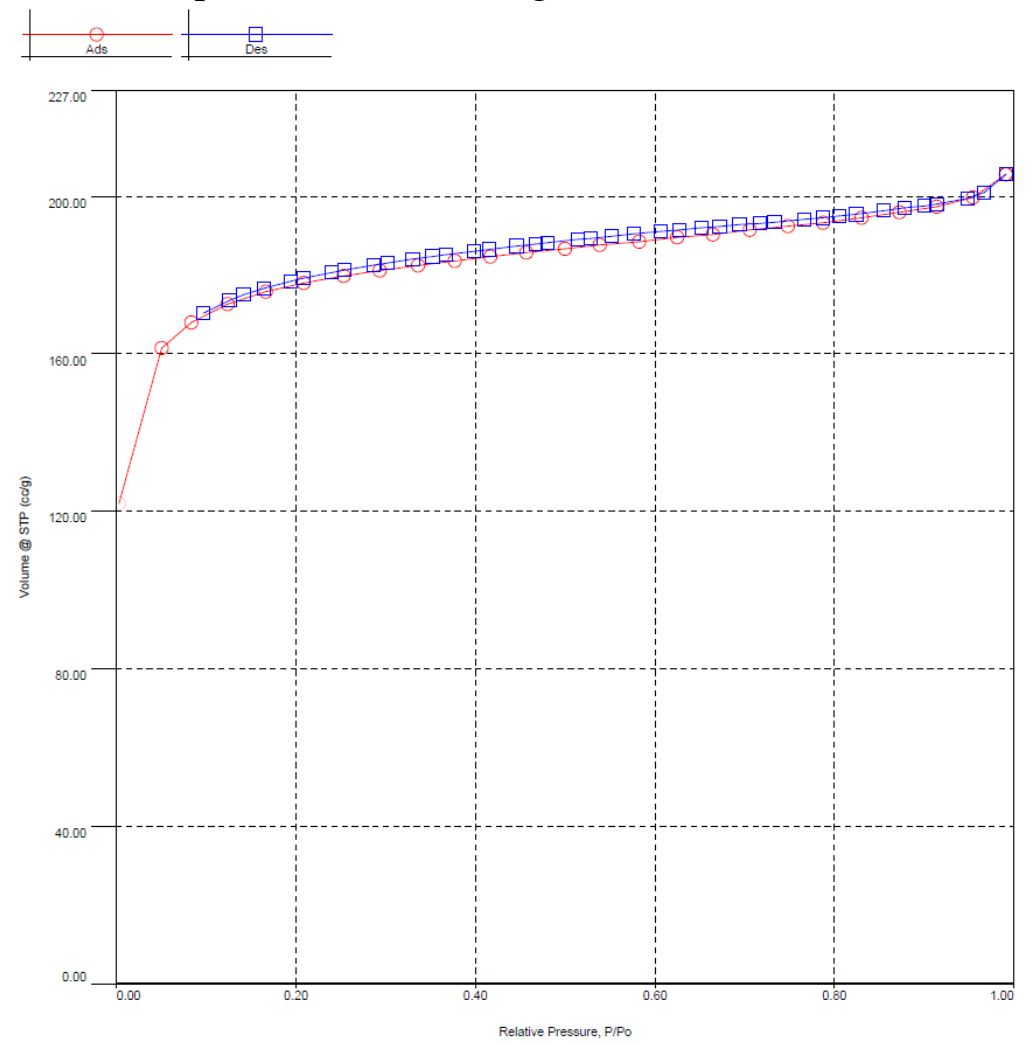

Figure 1. The adsorption-desorption isotherm of mesoporous material.

3.2. FT-IR characterization of the mesoporous material and loaded materials.

FT-IR analysis was performed for those mesoporous materials to confirm the template agent's extraction with ultrapure water and the successful loading with volatile wormwood oil.

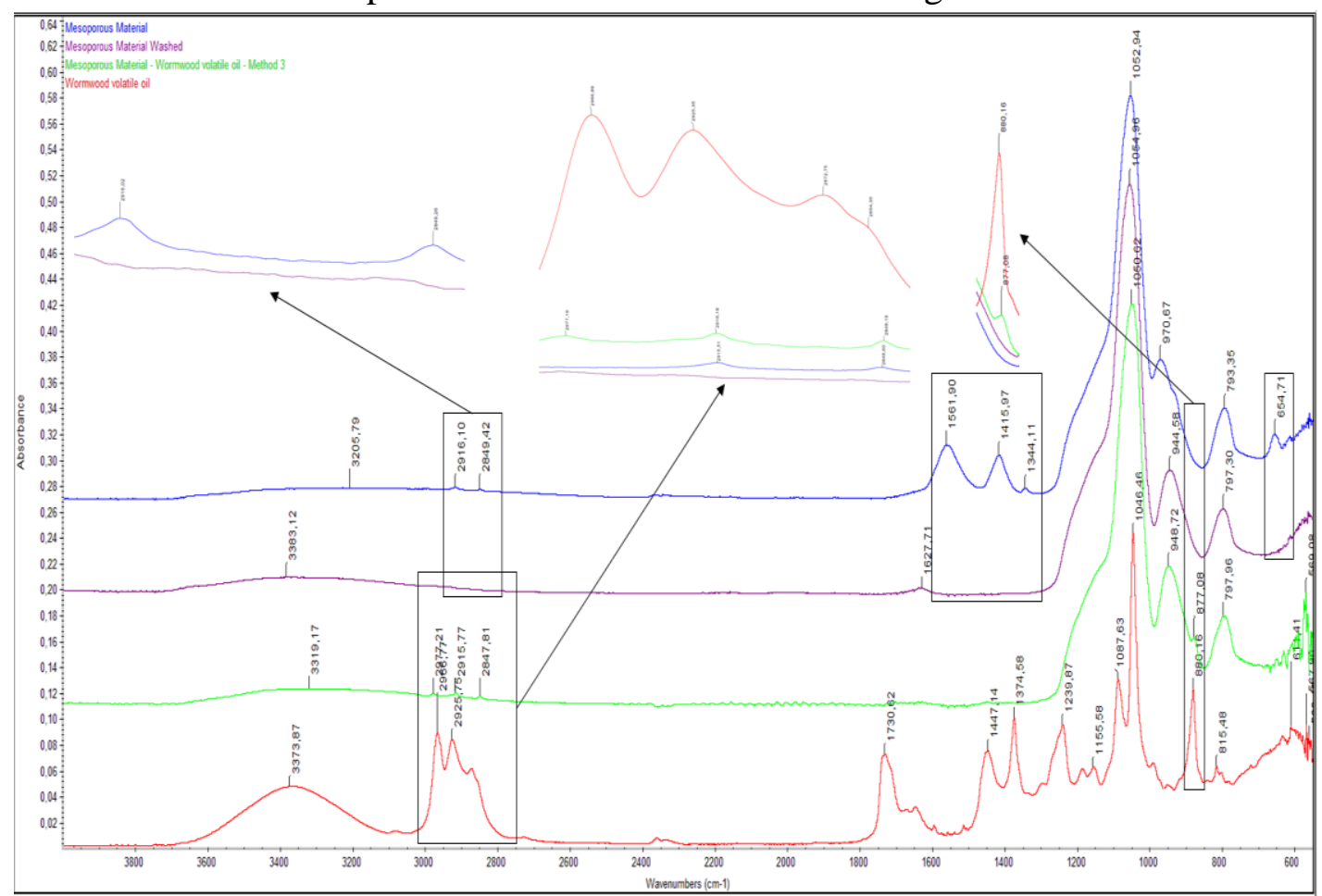

Figure 2. FT-IR spectra of the bulk, processed, loaded mesoporous material and Artemisia absinthium volatile oil. 
Comparing the FT-IR spectra of the synthesized mesoporous material with the processed mesoporous material, the bands corresponding to the template (stearic acid), 2916,10 $\mathrm{cm}^{-1} ; 2848,42 \mathrm{~cm} ; 1561,90 \mathrm{~cm}^{1} ; 1415,97 \mathrm{~cm}^{-1} ; 1344,11 \mathrm{~cm}^{-1}, 1561,90 \mathrm{~cm}^{-1} ; 1415,97 \mathrm{~cm}^{-1}$; $1344,11 \mathrm{~cm}^{-1}$ and $654,71 \mathrm{~cm}^{-1}$ no longer exists in the processed material spectrum. This result highlights the template removal process efficacy (Figure 2).

Comparing the FT-IR spectra of the processed material and volatile wormwood oil with the spectrum of one of the loaded materials (the one with the most representative spectral peaks for volatile oil) highlights the proof of the loading process. The spectral peaks from the loaded material spectrum linked to the volatile oil presence are $2977,21 \mathrm{~cm}^{-1} ; 2915,77 \mathrm{~cm}^{-1}, 2848,19$ $\mathrm{cm}^{-1}$ and $877,08 \mathrm{~cm}^{1}$ (Figure 2) are correlated with those from the volatile oil spectrum 2966,77 $\mathrm{cm}^{-1} ; 2925,75 \mathrm{~cm}^{-1}$ and $880,16 \mathrm{~cm}^{1}$.

Regarding the comparison between loading methods, the FT-IR spectra show that the selected methods are very similar, with a slight advantage for method 3 (Figure 3).

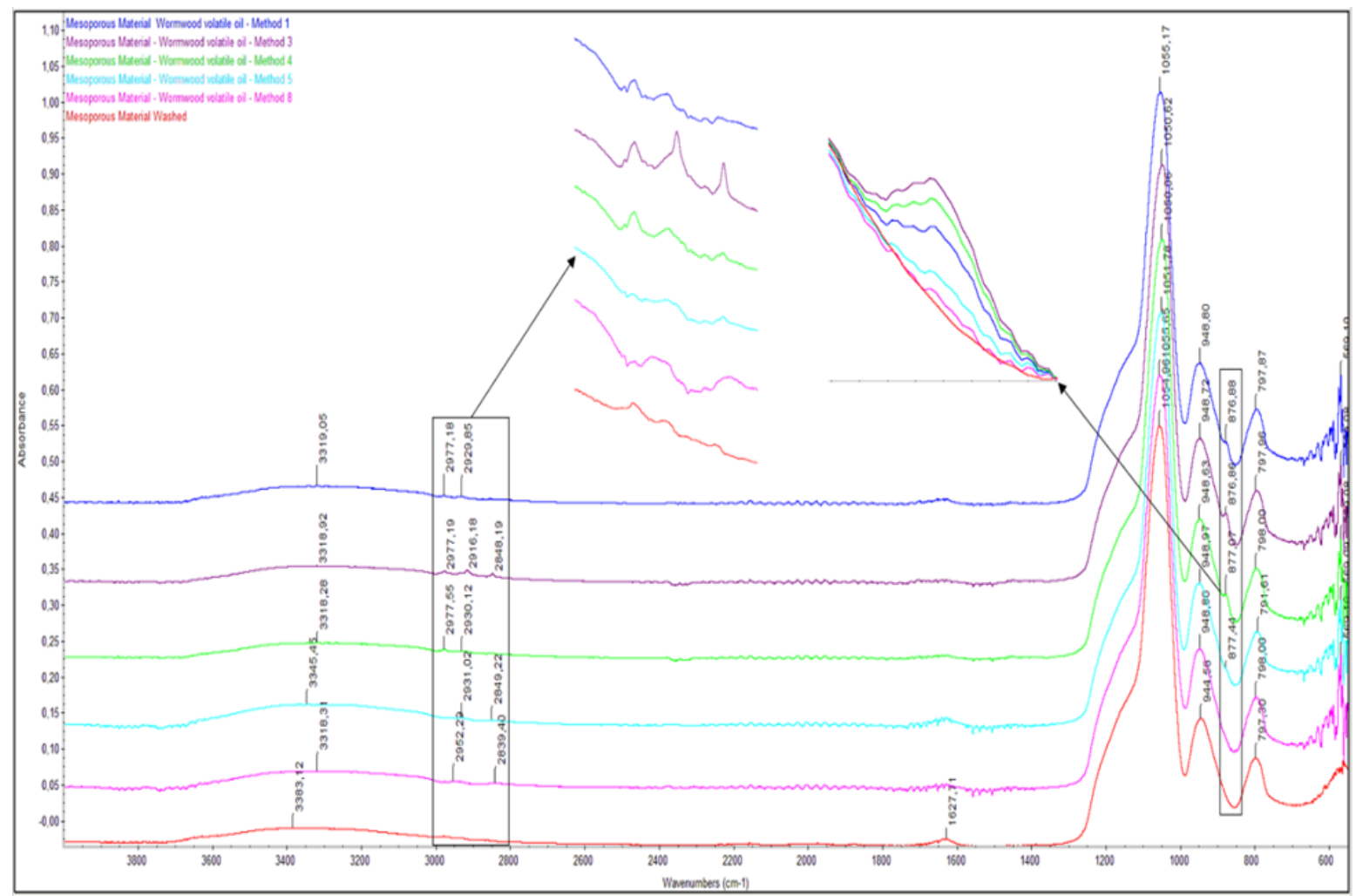

Figure 3. FT-IR spectra of loaded materials performed with selected loading methods.

\subsection{GC-MS analysis of loaded mesoporous materials.}

The concentrated wormwood volatile oil consisting of 1,5 $\mathrm{mL}$ oil and $2 \mathrm{~mL}$ ethanol), was diluted 1/50 with ethyl acetate and analyzed. Following the chromatographic profile analysis, 48 volatile components were identified (using the specialized compounds spectrum library), among the most important compounds with anthelmintic action recognized being $\alpha, \beta$ thujone, $\alpha$-terpinene, cymene, limonene, eucalyptol, terpineol, linalool, terpinen-4-ol, cisgeraniol, carvacrol, eugenol, caryophyllene, $\beta$-selinene, caryophyllene oxide (Figure 4) [1721].

Expressed as a percentage of the total areas of the identified compounds, $\beta$-myrcene and sabinene are the most abundant components from wormwood volatile oil, with $15.4 \%$ respectively $10.5 \%$ (Table 2 ). Slighty under $7 \%$, are represented by linalool $(6.45 \%)$, 
eucalyptol (5.64 \%), lavandulyl isovalerate (5.88 \%), geranyl isovalerianate (5.99\%), and gerany-p-cymene $(6.85 \%)$. In small percentage it can be found components like $\alpha$-thujene $(0.19 \%)$, ß-ocimene $(0.15 \%)$, trans-2-menthenol $(0.19 \%)$, nerol-oxide $(0.12 \%)$, sabina ketone $(0.09 \%)$, etc.

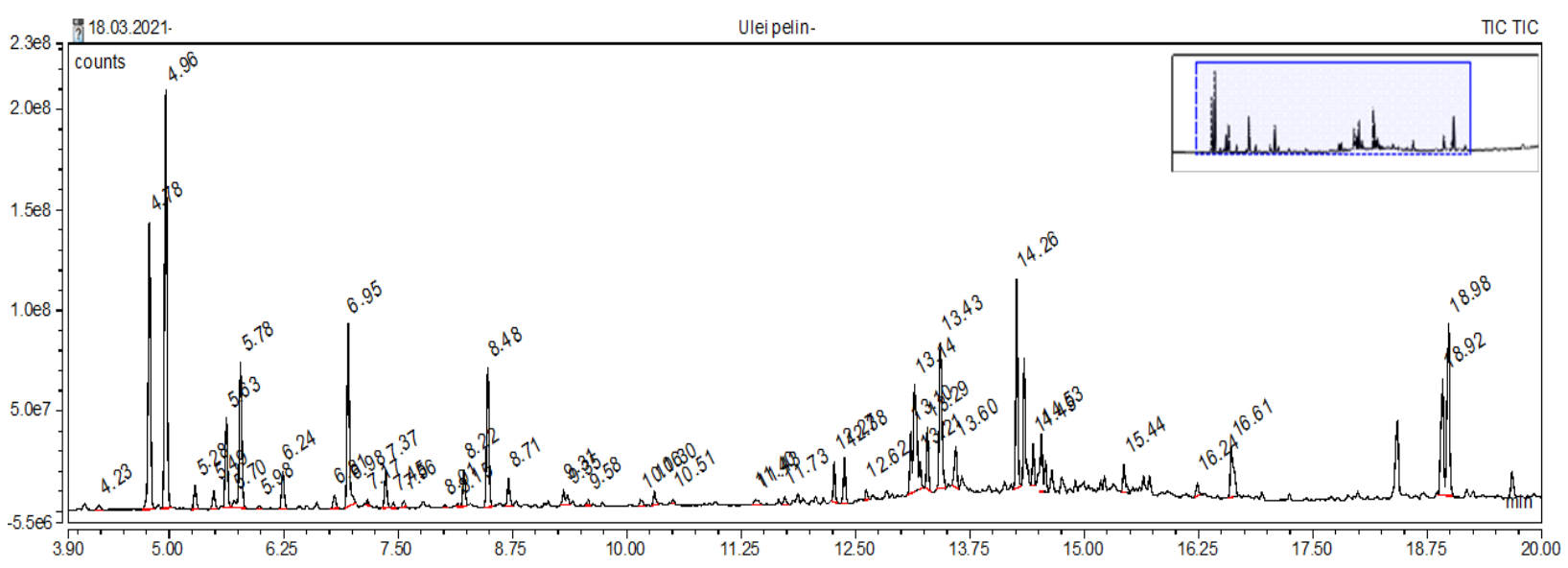

Figure 4. Chromatographic profile of volatile wormwood oil.

Table 2. Total area percentage of components identified volatile wormwood oil.

\begin{tabular}{|c|c|c|c|}
\hline No. & Peak Name & Retention time (min) & Area \% \\
\hline 1 & a-Thujene & 4.23 & 0.19 \\
\hline 2 & Sabinene & 4.78 & 10.45 \\
\hline 3 & B-Myrcene & 4.96 & 15.41 \\
\hline 4 & a-Phellandrene & 5.28 & 0.89 \\
\hline 5 & alfa-Terpinene & 5.49 & 0.65 \\
\hline 6 & o-Cymene & 5.63 & 3.32 \\
\hline 7 & L-Limonene & 5.7 & 0.37 \\
\hline 8 & Eucalyptol & 5.78 & 5.64 \\
\hline 9 & B-Ocimene & 5.98 & 0.15 \\
\hline 10 & gamma-Terpinen & 6.24 & 1.39 \\
\hline 11 & Terpinolene & 6.81 & 0.52 \\
\hline 12 & Linalool & 6.95 & 6.45 \\
\hline 13 & Perillen & 7 & 0.33 \\
\hline 14 & alpha-Thujone & 7.17 & 0.16 \\
\hline 15 & beta-Thujone & 7.37 & 1.31 \\
\hline 16 & trans-2-Menthenol & 7.45 & 0.19 \\
\hline 17 & B-Ocimene epoxide & 7.56 & 0.24 \\
\hline 18 & Nerol-oxide & 8.01 & 0.12 \\
\hline 19 & Sabina ketone & 8.15 & 0.09 \\
\hline 20 & $( \pm)$-Lavandulol & 8.22 & 1.29 \\
\hline 21 & Terpinen-4-ol & 8.48 & 5 \\
\hline 22 & alpha-Terpineol & 8.71 & 0.98 \\
\hline 23 & cis-Geraniol & 9.31 & 0.43 \\
\hline 24 & Myrtanol acetate & 9.35 & 0.33 \\
\hline 25 & Cumaldehyde & 9.58 & 0.2 \\
\hline 26 & Perillaldehyde & 10.16 & 0.29 \\
\hline 27 & Lavandulyl acetate & 10.3 & 0.53 \\
\hline 28 & Carvacrol & 10.51 & 0.21 \\
\hline 29 & Eugenol & 11.4 & 0.2 \\
\hline 30 & Nerol acetate & 11.43 & 0.19 \\
\hline 31 & alfa-Copaene & 11.73 & 0.3 \\
\hline 32 & Lavandulyl butyrate & 12.27 & 1.11 \\
\hline 33 & Caryophyllene & 12.38 & 1.43 \\
\hline 34 & B-Sesquiphellandrene & 12.62 & 0.36 \\
\hline 35 & ß-Himachalene & 13.1 & 1.8 \\
\hline 36 & a-Curcumene & 13.14 & 3.28 \\
\hline 37 & B-copaene & 13.21 & 0.83 \\
\hline 38 & beta-Selinene & 13.29 & 1.82 \\
\hline 39 & Lavandulyl isovalerate & 13.43 & 5.88 \\
\hline
\end{tabular}




\begin{tabular}{c|c|c|c} 
No. & Peak Name & Retention time (min) & Area \% \\
\hline 40 & 3,6-Dihydrochamazulene & 13.6 & 1.56 \\
\hline 41 & Geranyl isovalerianate & 14.26 & 5.99 \\
\hline 42 & Spathulenol & 14.45 & 1.15 \\
\hline 43 & Caryophyllene oxide & 14.53 & 2.49 \\
\hline 44 & Intermedeol & 15.44 & 0.66 \\
\hline 45 & Chamazulene & 16.24 & 0.47 \\
\hline 46 & Costol & 16.61 & 1.67 \\
\hline 47 & geranyl-alfa-terpinene & 18.92 & 4.87 \\
\hline 48 & Gerany-p-cymene & 18.98 & 6.85
\end{tabular}

Certain volatile compounds (eucalyptol, linalool, myrcene, cymene, and $\alpha, \beta$ thujone) were subjected to quantitative determination by using 6 levels of calibration. Linearity ranges: B-myrcene 9.2-462 $\mu \mathrm{g} / \mathrm{ml}$, o-cymene 2.4-121 $\mu \mathrm{g} / \mathrm{ml}$, eucalyptol 1.8-90 $\mu \mathrm{g} / \mathrm{ml}$, linalool 7.8-390 $\mu \mathrm{g} / \mathrm{ml}$, sum of $\alpha, \beta$ thujone $1.7-86 \mu \mathrm{g} / \mathrm{ml}$, with the regression factor $\mathrm{R}^{2}>0.998$. (Figure 5).

By using the regression equation of each individual compound calibrated, it were quantified $28.8 \mathrm{mg} / \mathrm{mL}$ myrcene, $3.5 \mathrm{mg} / \mathrm{mL}$ cymene, $7.5 \mathrm{mg} / \mathrm{mL}$ eucalyptol, $31.8 \mathrm{mg} / \mathrm{mL}$ linalool, and $3.05 \mathrm{mg} / \mathrm{mL}$ sum of $\alpha, \beta$ thujone from volatile wormwood oil, diluted in ethanol.

To evaluate the highest load capacity of the identified volatile components, small amounts $(200 \mathrm{mg}$ ) of mesoporous material were weighed in $50 \mathrm{~mL}$ flasks, for which the loading methods mentioned above have been applied. Following the B.E.T. analysis, where the results show that specific area, volume, and the diameter parameters of the pores it is enough to allow the process, we decided that the synthesized mesoporous material be loaded with volatile oil in a proportion of $30 \%$ (mass ratio $\mathrm{w} / \mathrm{w}$ ).

About $50 \mathrm{mg}$ of mesoporous material loaded with volatile oil (30\%) was dispersed in $1 \mathrm{~mL}$ of ethyl acetate, which was subjected to ultrasonication, centrifugation, and filtration process, before analysis. According to the data, the most effective loading method is method 8 , where the recoveries of the quantified compounds were: $14.1 \%$ myrcene, $25.8 \%$ cymene, $64.4 \%$ eucalyptol, $90.2 \%$ linalool, and the sum of $\alpha, \beta$ thujone $65.9 \%$, followed by method $5>$ method 3> method $4>$ method $1>$ method 2. Comparing all the proposed loading methods, the third was the worst option, being found $5.7 \%$ myrcene, $10 \%$ cymene, $17.1 \%$ eucalyptol, $19.5 \%$ linalool, and $20.4 \% \alpha, \beta$ thujone, from the theoretical amount of loaded compounds (Figure 6).

Due to the relatively low boiling points of volatile compounds, it's possible that in the loading process, some of them may be lost or evaporated together with ethyl alcohol or methanol, used as solvents for the initial dispersion of the components in the pores of materials.

Another control made to evaluate both the loading capacity of the mesoporous material and the competition between oil's components for the available surface was the loading of two different amounts of $\alpha, \beta$ thujone, one similar to that found in the volatile oil $(0.03 \mathrm{mg} / \mathrm{mL})$ and another at a much higher level $(30 \mathrm{mg} / \mathrm{mL})$. The results show, in both cases, an average loading of around $55 \%$ (52.8\% for the first solution and 56.9\% for the second one), slightly below the values obtained for the others oil loading methods. This is a confirmation of the assumption that the pores filling process does not interfere with the fact that the oil has a mixed composition, with different behavior and affinity on each component.

Also, it was calculated the recovery $\%$ of each component identified in the proposed loading methods by reporting the obtained areas (for each variant) to the initial area's results for volatile wormwood oil diluted in ethanol, used as a reference, at the same concentration. 

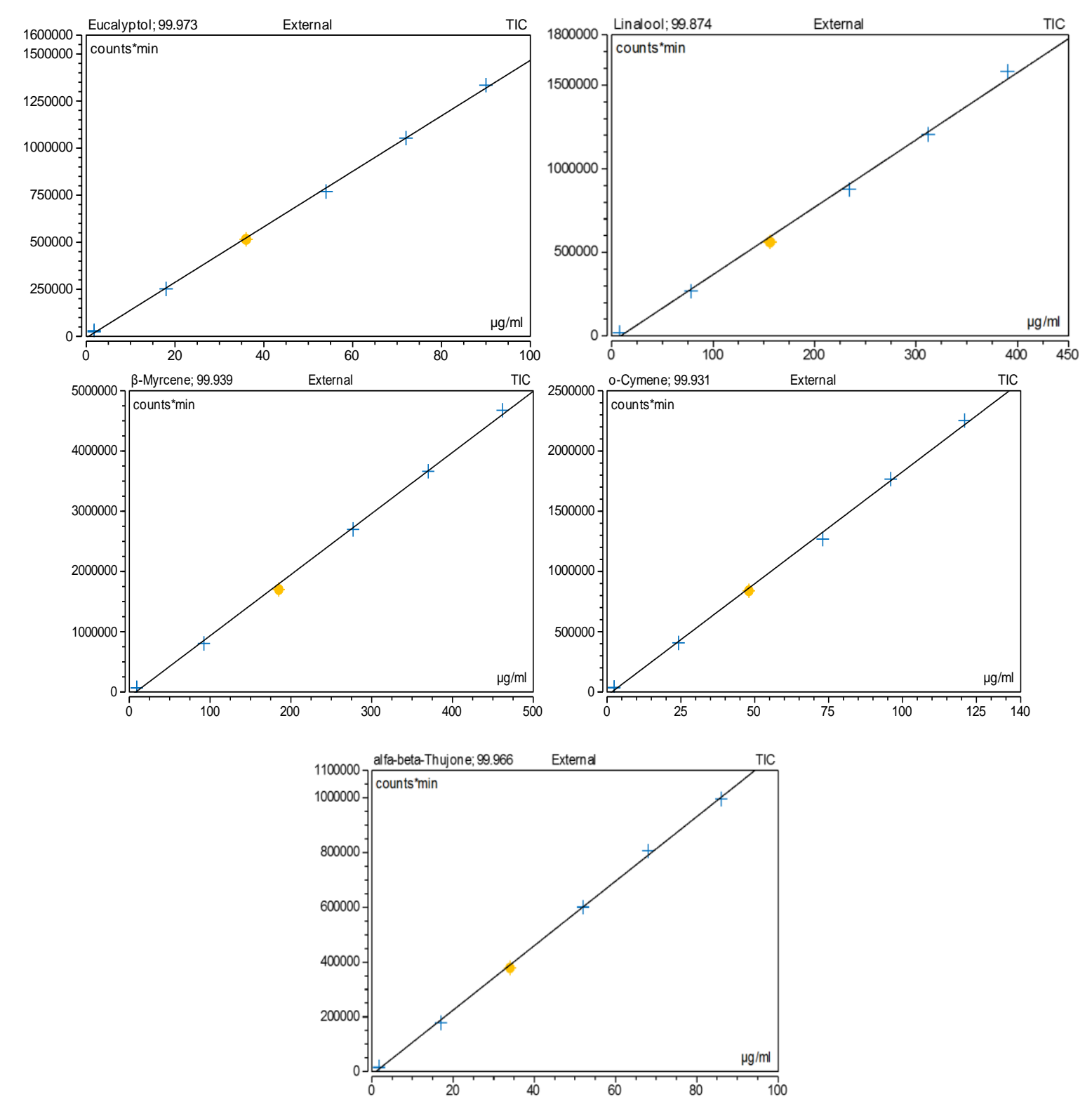

1 1 18.03.2021-teste UV-incarcare \#3

C1-0.0211

2-18.03.2021-teste UV-incarcare\#4 [manuallyintegrated]

C2-0.21

C3-0.411

C4.0.611

3-18.03.2021-teste UV-incarcare \#5 [manually integrated]

4-18.03.2021-teste UV-incarcareft6[manuallyintegrated]

$1.5 e 83$

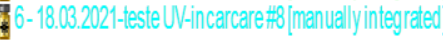

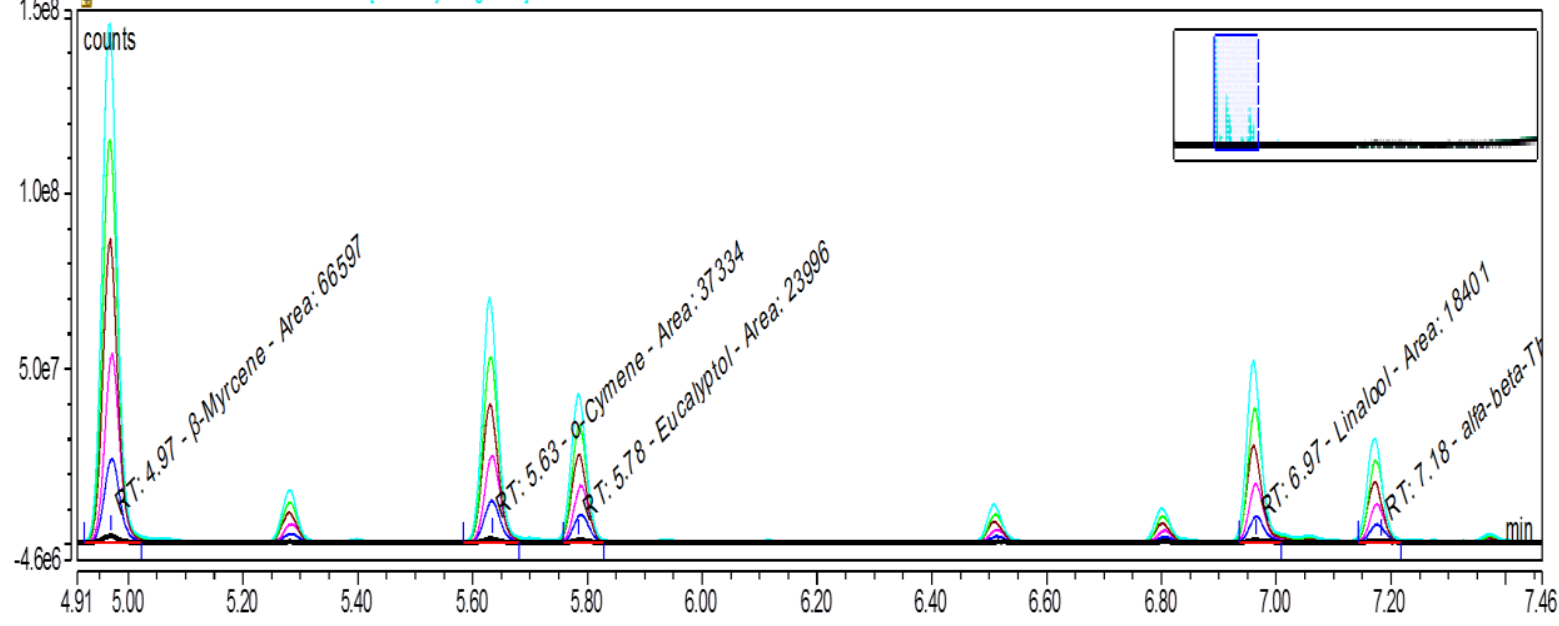

Figure 5. Overlapping chromatograms of the calibration points of $\beta$-myrcene, cymene, eucalyptol, linalool, and $\alpha, \beta$ thujone. 


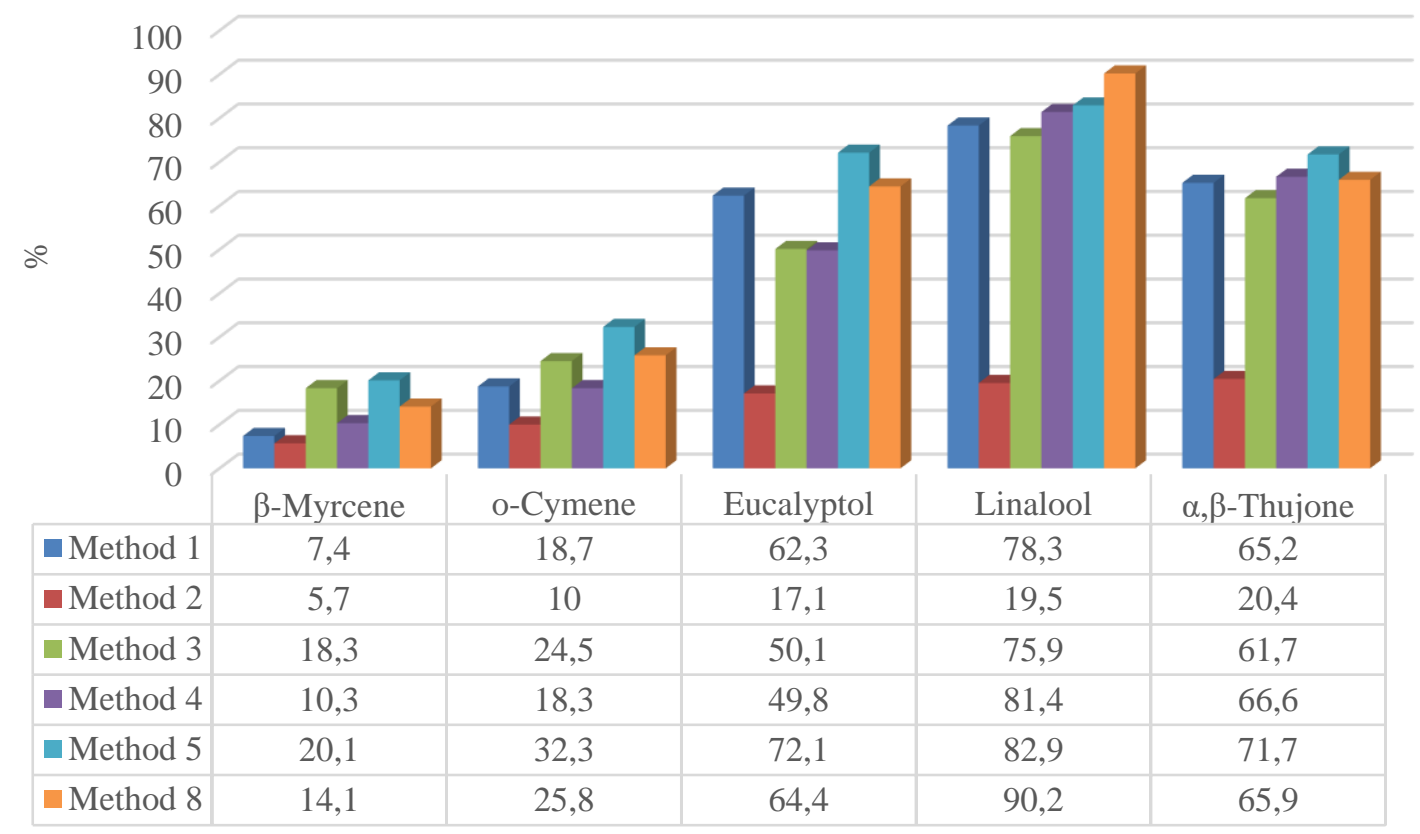

Figure 6. The percentage recovery of calibrated components using different methods of loading.

Table 3. The percentage recovery of total components identified using different methods of loading.

\begin{tabular}{|c|c|c|c|c|c|c|c|}
\hline $\begin{array}{l}\text { Nr. } \\
\text { crt. }\end{array}$ & Compounds & Method 1 & Method 2 & Method 3 & Method 4 & Method 5 & Method 8 \\
\hline 1 & Sabinene & 1.61 & 2.15 & 8.36 & 2.52 & 6.64 & 2.86 \\
\hline 2 & B-Myrcene & 4.32 & 3.16 & 13.18 & 6.67 & 14.67 & 6.51 \\
\hline 3 & a-Phellandrene & 5.64 & 2.29 & 16.11 & 5.34 & 17.85 & 6.46 \\
\hline 4 & alfa-Terpinene & 9.51 & 3.60 & 17.10 & 11.44 & 10.27 & 6.00 \\
\hline 5 & o-Cymene & 12.99 & 6.00 & 17.99 & 12.64 & 24.61 & 14.00 \\
\hline 6 & L-Limonene & 66.92 & 27.63 & 44.87 & 67.47 & 88.40 & 74.49 \\
\hline 7 & Eucalyptol & 52.10 & 14.71 & 41.78 & 41.48 & 60.33 & 50.62 \\
\hline 8 & B-Ocimene & 47.12 & 17.08 & 56.76 & 47.68 & 84.78 & 76.45 \\
\hline 9 & gamma-Terpinen & 14.78 & 5.47 & 23.67 & 17.58 & 30.15 & 15.64 \\
\hline 10 & Terpinolene & 41.04 & 12.07 & 46.38 & 42.48 & 57.11 & 45.11 \\
\hline 11 & Linalool & 63.06 & 16.09 & 64.05 & 66.91 & 69.46 & 70.28 \\
\hline 12 & Perillen & 38.3 & 38.41 & 63.78 & 34.8 & 50.8 & 45.3 \\
\hline 13 & alpha-Thujone & 60.06 & 18.97 & 53.98 & 46.12 & 73.26 & 45.06 \\
\hline 14 & beta-Thujone & 59.22 & 15.67 & 51.60 & 54.66 & 60.65 & 58.96 \\
\hline 15 & trans-2-Menthenol & 15.32 & 10.99 & 57.38 & 39.53 & 61.08 & 46.66 \\
\hline 16 & B-Ocimene epoxide & 9.16 & 24.98 & 68.56 & 65.20 & 77.40 & 87.96 \\
\hline 17 & Nerol-oxide & 59.09 & 6.98 & 55.09 & 44.31 & 69.98 & 56.85 \\
\hline 18 & Sabina ketone & 50.48 & 33.68 & 63.22 & 77.43 & 63.59 & 66.95 \\
\hline 19 & $( \pm)$-Lavandulol & 52.79 & 14.67 & 56.99 & 58.34 & 63.27 & 60.99 \\
\hline 20 & Terpinen-4-ol & 66.54 & 18.07 & 67.37 & 69.20 & 74.65 & 72.68 \\
\hline 21 & alpha-Terpineol & 62.60 & 17.45 & 65.75 & 74.91 & 83.54 & 70.73 \\
\hline 22 & cis-Geraniol & 62.17 & 14.48 & 51.68 & 73.16 & 79.18 & 80.91 \\
\hline 23 & Myrtanol acetate & 61.9 & 20.69 & 66.27 & 76.1 & 61.6 & 64.1 \\
\hline 24 & Cumaldehyde & 54.72 & 10.58 & 48.96 & 62.82 & 89.76 & 70.19 \\
\hline 25 & Perillaldehyde & 76.83 & 16.72 & 55.99 & 63.48 & 69.00 & 67.69 \\
\hline 26 & Lavandulyl acetate & 55.65 & 29.54 & 46.01 & 59.99 & 80.22 & 66.39 \\
\hline 27 & Carvacrol & 34.01 & 7.85 & 48.71 & 52.45 & 84.93 & 83.01 \\
\hline 28 & Eugenol & 28.30 & 15.70 & 44.92 & 31.21 & 50.53 & 42.84 \\
\hline 29 & Nerol acetate & 42.06 & 24.32 & 48.67 & 50.68 & 71.88 & 47.10 \\
\hline 30 & alfa-Copaene & 72.25 & 21.69 & 61.29 & 62.47 & 71.01 & 54.05 \\
\hline 31 & Lavandulyl butyrate & 75.03 & 23.28 & 64.15 & 78.47 & 78.04 & 67.14 \\
\hline 32 & Caryophyllene & 35.15 & 17.86 & 63.00 & 58.67 & 73.65 & 58.16 \\
\hline
\end{tabular}




\begin{tabular}{c|c|c|c|c|c|c|c}
\hline $\begin{array}{l}\text { Nr. } \\
\text { crt. }\end{array}$ & Compounds & Method 1 & Method 2 & Method 3 & Method 4 & Method 5 & Method 8 \\
\hline 33 & B-Sesquiphellandrene & 1.72 & 17.31 & 67.49 & 48.08 & 63.97 & 49.46 \\
\hline 34 & B-Himachalene & 29.36 & 9.51 & 63.46 & 32.08 & 36.34 & 30.02 \\
\hline 35 & a-Curcumene & 74.11 & 28.49 & 73.97 & 54.80 & 56.77 & 57.54 \\
\hline 36 & ß-copaene & 10.12 & 29.07 & 77.48 & 15.75 & 41.87 & 15.09 \\
\hline 37 & beta-Selinene & 53.03 & 22.60 & 72.77 & 67.24 & 71.90 & 60.78 \\
\hline 38 & Lavandulyl isovalerate & 73.66 & 17.34 & 77.33 & 76.89 & 77.40 & 76.05 \\
\hline 39 & 3,6 -Dihydrochamazulene & 0.55 & 3.13 & 72.85 & 20.08 & 40.50 & 30.04 \\
\hline 40 & Geranyl isovalerianate & 67.78 & 16.20 & 71.75 & 71.88 & 71.45 & 71.65 \\
\hline 41 & Spathulenol & 63.82 & 24.08 & 69.77 & 76.48 & 88.66 & 87.45 \\
\hline 42 & Caryophyllene oxide & 38.96 & 59.25 & 71.45 & 72.31 & 74.51 & 81.84 \\
\hline 43 & Intermedeol & 48.32 & 24.70 & 71.67 & 68.02 & 67.52 & 64.22 \\
\hline 44 & Chamazulene & 6.3 & 11.9 & 66.96 & 39.7 & 84.4 & 52.02 \\
\hline 45 & Costol & 44.47 & 14.56 & 69.61 & 57.75 & 56.42 & 59.29 \\
\hline 46 & geranyl-alfa-terpinene & 46.10 & 14.68 & 74.84 & 62.72 & 81.56 & 59.80 \\
\hline 47 & Gerany-p-cymene & 52.09 & 16.92 & 78.85 & 70.66 & 83.15 & 63.37
\end{tabular}

The results show that with the decreasing of the volatility of the components, the recovery is higher, obtaining, in a certain situation, a recovery close to the initial values of the wormwood oil component concentration (linalool 63-70.3\%, terpinen-4-ol 62.6-83.5\%, lavandulyl butyrate $73.6-77.4 \%$, spathulenol $63.8-88.7 \%$, etc.). The recovery of the compounds sabinene, $\beta$-myrcene, a-phellandrene, alfa-terpinene, and o-cymene, located in the first part of the chromatogram, are small and varied due to their low boiling temperatures. $\alpha$ Thujene, the first compound identified in wormwood oil chromatogram, is poorly detected; therefore, it was not taken into account.

\subsection{Statistical analysis of the loading techniques efficacy.}

There was a statistically significant difference between groups determined by one-way ANOVA $(F(5,276)=27.595, p=0.001)$, based on results obtained from SPSS Statistics (Table 4).

Table 4. Results obtained from SPSS Statistics, using one-way ANOVA.

\begin{tabular}{c|c|c|c|c|c} 
Source & $\begin{array}{c}\text { Sum of Squares } \\
\text { (SS) }\end{array}$ & $\begin{array}{c}\text { df } \\
\text { (degrees of } \\
\text { freedom) }\end{array}$ & $\begin{array}{c}\text { Mean Square } \\
\text { (MS) }\end{array}$ & F & $\begin{array}{c}\text { Sig. } \\
\text { (p value) }\end{array}$ \\
\hline Between Groups & 62862.374 & 5 & 12572.475 & 27.595 & $<0.001$ \\
\hline Within Groups & 125748.932 & 276 & 455.612 & &
\end{tabular}

Analysis of variance revealed significant differences between groups ( $\mathrm{p}$ value $<0.001$ ), and subsequent post hoc analysis showed significant differences between certain groups (Table $5)$.

Table 5. Multiple comparisons with the results of the Tukey post hoc test.

\begin{tabular}{|c|c|c|c|c|c|c|c|}
\hline \multirow[b]{2}{*}{$\begin{array}{l}\text { (I) Run } \\
\text { Number }\end{array}$} & \multirow[b]{2}{*}{$\begin{array}{c}\text { (J) Run } \\
\text { Number }\end{array}$} & & \multirow{2}{*}{$\begin{array}{l}\text { Mean } \\
\text { Difference (I- } \\
\text { J) }\end{array}$} & \multirow[b]{2}{*}{ Std. Error } & \multirow[b]{2}{*}{$\begin{array}{c}\text { Sig. } \\
\text { (p value) }\end{array}$} & \multicolumn{2}{|c|}{ 95\% Confidence Interval } \\
\hline & & & & & & $\begin{array}{l}\text { Lower } \\
\text { Bound }\end{array}$ & $\begin{array}{l}\text { Upper } \\
\text { Bound }\end{array}$ \\
\hline \multirow{8}{*}{$\begin{array}{l}\text { Tukey } \\
\text { HSD }\end{array}$} & \multirow{5}{*}{ Method 1} & M 2 & $26.92809^{*}$ & 4.40315 & $<0.001$ & 14.2917 & 39.5645 \\
\hline & & M 3 & -11.47489 & 4.40315 & 0.099 & -24.1113 & 1.1615 \\
\hline & & M 4 & -9.44128 & 4.40315 & 0.268 & -22.0777 & 3.1951 \\
\hline & & M 5 & $-19.41723^{*}$ & 4.40315 & $<0.001$ & -32.0536 & -6.7808 \\
\hline & & M 8 & -10.46383 & 4.40315 & 0.168 & -23.1002 & 2.1726 \\
\hline & \multirow{3}{*}{ Method 2} & M 1 & $-26.92809^{*}$ & 4.40315 & $<0.001$ & -39.5645 & -14.2917 \\
\hline & & M 3 & $-38.40298^{*}$ & 4.40315 & $<0.001$ & -51.0394 & -25.7666 \\
\hline & & M 4 & $-36.36936^{*}$ & 4.40315 & $<0.001$ & -49.0058 & -23.7330 \\
\hline
\end{tabular}




\begin{tabular}{|c|c|c|c|c|c|c|c|}
\hline \multirow{24}{*}{$\begin{array}{c}\text { (I) Run } \\
\text { Number }\end{array}$} & \multirow{4}{*}{$\begin{array}{l}\text { (J) Run } \\
\text { Number }\end{array}$} & & \multirow{2}{*}{$\begin{array}{c}\text { Mean } \\
\text { Difference (I- } \\
\text { J) }\end{array}$} & \multirow[b]{2}{*}{ Std. Error } & \multirow[b]{2}{*}{$\begin{array}{c}\text { Sig. } \\
\text { (p value) }\end{array}$} & \multicolumn{2}{|c|}{ 95\% Confidence Interval } \\
\hline & & & & & & $\begin{array}{l}\text { Lower } \\
\text { Bound }\end{array}$ & $\begin{array}{l}\text { Upper } \\
\text { Bound }\end{array}$ \\
\hline & & M 5 & $-46.34532^{*}$ & 4.40315 & $<0.001$ & -58.9817 & -33.7089 \\
\hline & & M 8 & $-37.39191^{*}$ & 4.40315 & $<0.001$ & -50.0283 & -24.7555 \\
\hline & & M 1 & 11.47489 & 4.40315 & 0.099 & -1.1615 & 24.1113 \\
\hline & & M 2 & $38.40298^{*}$ & 4.40315 & $<0.001$ & 25.7666 & 51.0394 \\
\hline & Method 3 & M 4 & 2.03362 & 4.40315 & 0.997 & -10.6028 & 14.6700 \\
\hline & & M 5 & -7.94234 & 4.40315 & 0.465 & -20.5787 & 4.6941 \\
\hline & & M 8 & 1.01106 & 4.40315 & 1.000 & -11.6253 & 13.6475 \\
\hline & & M 1 & 9.44128 & 4.40315 & 0.268 & -3.1951 & 22.0777 \\
\hline & & M 2 & $36.36936^{*}$ & 4.40315 & $<0.001$ & 23.7330 & 49.0058 \\
\hline & Method 4 & M3 & -2.03362 & 4.40315 & 0.997 & -14.6700 & 10.6028 \\
\hline & & M 5 & -9.97596 & 4.40315 & 0.212 & -22.6124 & 2.6604 \\
\hline & & M 8 & -1.02255 & 4.40315 & 1.000 & -13.6590 & 11.6138 \\
\hline & & M 1 & $19.41723^{*}$ & 4.40315 & $<0.001$ & 6.7808 & 32.0536 \\
\hline & & M 2 & $46.34532^{*}$ & 4.40315 & $<0.001$ & 33.7089 & 58.9817 \\
\hline & Method 5 & M 3 & 7.94234 & 4.40315 & 0.465 & -4.6941 & 20.5787 \\
\hline & & M 4 & 9.97596 & 4.40315 & 0.212 & -2.6604 & 22.6124 \\
\hline & & M 8 & 8.95340 & 4.40315 & 0.326 & -3.6830 & 21.5898 \\
\hline & & M 1 & 10.46383 & 4.40315 & 0.168 & -2.1726 & 23.1002 \\
\hline & & M 2 & $37.39191^{*}$ & 4.40315 & $<0.001$ & 24.7555 & 50.0283 \\
\hline & Method 8 & M 3 & -1.01106 & 4.40315 & 1.000 & -13.6475 & 11.6253 \\
\hline & & M 4 & 1.02255 & 4.40315 & 1.000 & -11.6138 & 13.6590 \\
\hline & & M 5 & -8.95340 & 4.40315 & 0.326 & -21.5898 & 3.6830 \\
\hline
\end{tabular}

The obtained statistical data were summarized as follow: method 1 of loading show the significant difference over M 2 \& M 5; method 3, 4, and 8 show significant difference only with M 2; method 5 are significant difference over M $1 \&$ M 2; method 2 of loading are different over the all tested methods.

Table 6. Correlation matrix.

\begin{tabular}{|l|c|c|c|c|c|c|}
\hline & $\mathbf{1}$ & $\mathbf{2}$ & $\mathbf{3}$ & $\mathbf{4}$ & $\mathbf{5}$ & $\mathbf{8}$ \\
\hline $\mathbf{1}$ & 1 & & & & & \\
\hline $\mathbf{2}$ & 0.436098 & 1 & & & & \\
\hline $\mathbf{3}$ & 0.450397 & 0.534642 & 1 & & & \\
\hline $\mathbf{4}$ & 0.752597 & 0.603943 & 0.68228 & 1 & & \\
\hline $\mathbf{5}$ & 0.633397 & 0.48661 & 0.672227 & 0.85972 & 1 & \\
\hline $\mathbf{8}$ & 0.696927 & 0.535528 & 0.655078 & 0.85933 & 0.88964 & 1 \\
\hline
\end{tabular}

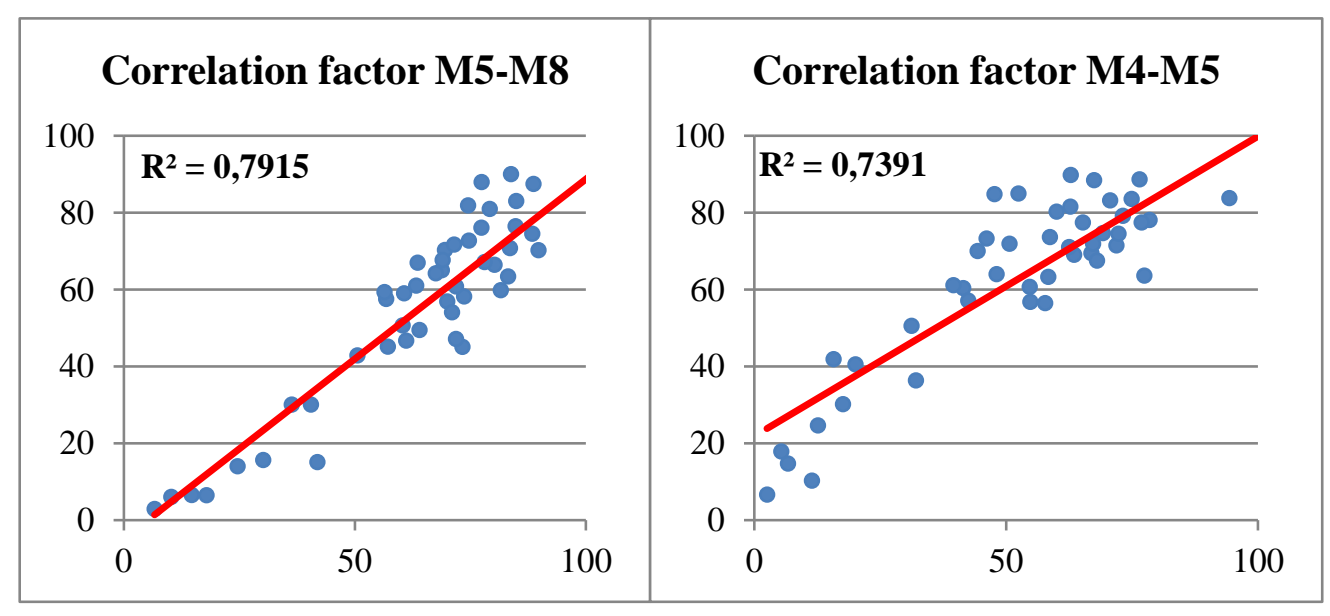




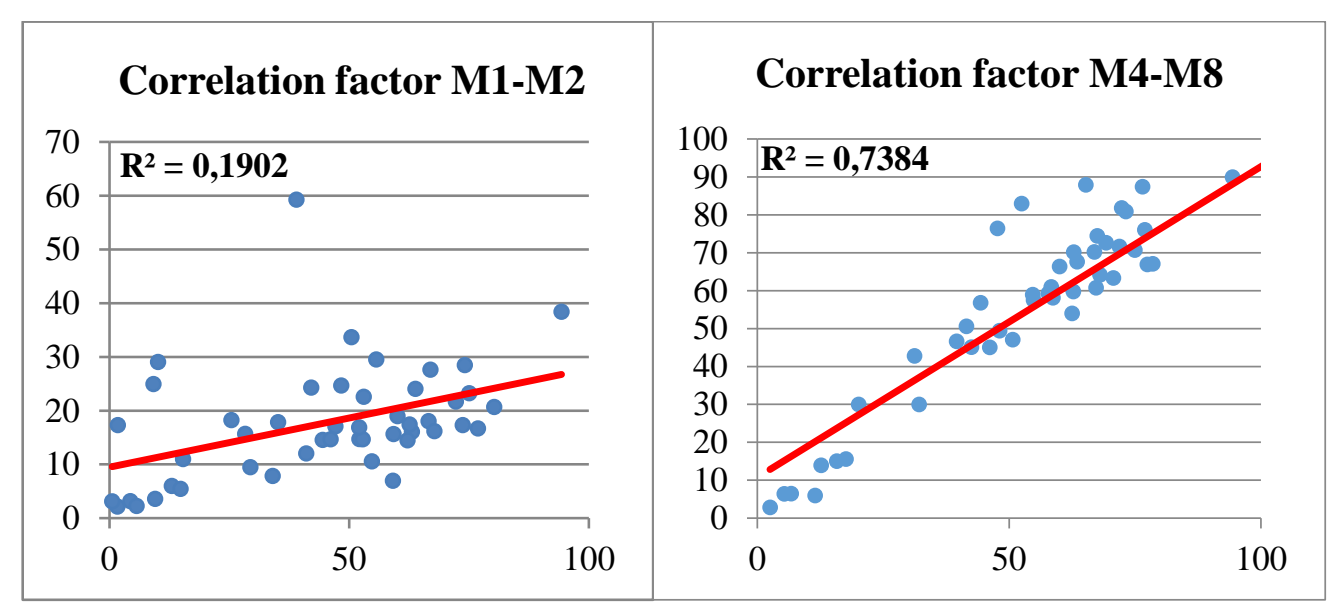

Figure 7. Correlation factors.

According to the correlation matrix, the best correlation factor is between M5-M8 $\left(\mathrm{R}^{2}=\right.$ 0.7915), M4-M5 $\left(R^{2}=0.7391\right)$, and M4-M8 $\left(R^{2}=0.7384\right)$, having a common parameter, the temperature at which the loading process took place. The worst correlation is between M1-M2, M1-M3, and M2-M5 (figure 7).

\section{Conclusions}

A high surface area mesoporous material was obtained from a trisilicate silica source and stearic acid template by a sol-gel method and used further as a matrix for essential oil loading. The A.absinthium essential oil was obtained by hydrodistillation and characterized by GC-MS.

The 8 different loading strategies were compared as total compound recovery after the loading process, and after the qualitative and quantitative analysis, followed by ANOVA statistical evaluation, the best loading method was selected. The loading process proves to be more efficient for the $2-5^{\circ} \mathrm{C} / \mathrm{N}_{2}$ flow method.

For the high concentration components (including $\alpha, \beta$ thujone, limonene, eucalyptol, terpineol, linalool, terpinen-4-ol, cis- geraniol, carvacrol, caryophyllene oxide, etc.), at least $46 \%$ recovery was obtained, excluding method 2 , with significantly lower recovery rate.

\section{Funding}

This research was funded by project: „Compozit multifunctional pe baza de matrice silicaorganica transpozabila pentru inovatii de produse si formulari particularizate in industria alimentara si farmaceutica", INNOVATIVE TECHNOLOGICAL PROJECT FOR MORE DEVELOPED REGIONS (Bucharest- Ilfov), Cod SMIS 122027, Contract no. 257/09.06.2020.

\section{Acknowledgments}

Competitiveness operational program (COP): Stimulating the demand of enterprises for innovation through RDI projects carried out by individual enterprises or in partnership with the R\&D institutes and universities to innovate processes and products in economic sectors with growth potential.

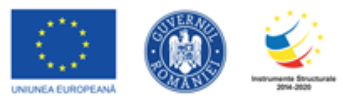




\section{Conflicts of Interest}

The authors declare no conflict of interest.

\section{References}

1. Janatova, A.; Bernardos, A.; Smid, J.; Frankova, A.; Lhotka, M.; Kourimská, L.; Pulkrabek, J.; Kloucek, P. Long-term antifungal activity of volatile essential oil components released from mesoporous silica materials. Industrial Crops and Products 2015, 67, 216-220, http://dx.doi.org/10.1016/j.indcrop.2015.01.019.

2. Jin, L.; Teng, J.; Hu, L.; Lan, X.; Xu, Y.; Sheng, J.; Song, Y.; Wang, M. Pepper fragrant essential oil (PFEO) and functionalized MCM-41 nanoparticles: formation, characterization, and bactericidal activity. J. Sci. Food Agric. 2019, 99, 5168-5175, https://doi.org/10.1002/jsfa.9776.

3. Gámez, E.; Elizondo-Castillo, H.; Tascon, J.; García-Salinas, S.; Navascues, N.; Mendoza, G.; Arruebo, M.; Irusta, S. Antibacterial Effect of Thymol Loaded SBA-15 Nanorods Incorporated in PCL Electrospun Fibers. Nanomaterials 2020, 10, https://doi.org/10.3390/nano10040616.

4. Edris, A.E. Pharmaceutical and therapeutic Potentials of essential oils and their individual volatile constituents: a review. Phytother. Res. 2007, 21, 308-323, https://doi.org/10.1002/ptr.2072.

5. Lidia-Ioana, V.; Cecilia, G.; Monica, M. Obtaining and Characterization of Volatile Oils from Aromatic Plants. In Proceedings of 1st International Symposium Innovations in Life Sciences (ISILS 2019) 2019, 7174, https://doi.org/10.2991/isils-19.2019.83.

6. Irshad, M.; Subhani, M.A.; Ali, S.; Hussain, A. Biological importance of essential oils. In Essential Oils-Oils of Naturei, IntechOpen, 2020, https://doi.org/10.5772/intechopen.87198.

7. Batiha, G.E.; Olatunde, A.; El-Mleeh, A.; Hetta, H.F.; Al-Rejaie, S.; Alghamdi, S.; Zahoor, M.; Magdy Beshbishy, A.; Murata, T.; Zaragoza-Bastida, A.; Rivero-Perez, N. Bioactive Compounds, Pharmacological Actions, and Pharmacokinetics of Wormwood (Artemisia absinthium). Antibiotics 2020, 9, https://doi.org/10.3390/antibiotics9060353.

8. Benkhaled, A.; Boudjelal, A.; Napoli, E.; Baali, F.; Ruberto, G. Phytochemical profile, antioxidant activity and wound healing properties of Artemisia absinthium essential oil. Asian Pacific Journal of Tropical Biomedicine 2020, 10, 496, https://doi.org/10.4103/2221-1691.294089.

9. Aati, H.Y.; Perveen, S.; Orfali, R.; Al-Taweel, A.M.; Aati, S.; Wanner, J.; Khan, A.; Mehmood, R. Chemical composition and antimicrobial activity of the essential oils of Artemisia absinthium, Artemisia scoparia, and Artemisia sieberi grown in Saudi Arabia. Arabian Journal of Chemistry 2020, 13, 8209-8217, https://doi.org/10.1016/j.arabjc.2020.09.055.

10. Beshay, E.V.N. Therapeutic efficacy of Artemisia absinthium against Hymenolepis nana: in vitro and in vivo studies in comparison with the anthelmintic praziquantel. J. Helminthol. 2018, 92, 298-308, https://doi.org/10.1017/S0022149X17000529.

11. Szopa, A.; Pajor, J.; Klin, P.; Rzepiela, A.; Elansary, H.O.; Al-Mana, F.A.; Mattar, M.A.; Ekiert, H. Artemisia absinthium L.- Importance in the History of Medicine, the Latest Advances in Phytochemistry and Therapeutical, Cosmetological and Culinary Uses. Plants 2020, 9, https://doi.org/10.3390/plants9091063.

12. Horky, P.; Skalickova, S.; Smerkova, K.; Skladanka, J. Essential Oils as a Feed Additives: Pharmacokinetics and Potential Toxicity in Monogastric Animals. Animals 2019, 9, https://doi.org/10.3390/ani9060352.

13. Bravo Cadena, M.; Preston, G.M.; Van der Hoorn, R.A.L.; Townley, H.E.; Thompson, I.P. Species-specific antimicrobial activity of essential oils and enhancement by encapsulation in mesoporous silica nanoparticles. Industrial Crops and Products 2018, 122, 582-590, https://doi.org/10.1016/j.indcrop.2018.05.081.

14. Seljak, K.B.; Kocbek, P.; Gašperlin, M. Mesoporous silica nanoparticles as delivery carriers: An overview of drug loading techniques. J. Drug Deliv. Sci. Technol. 2020, 59, 101906, https://doi.org/10.1016/j.jddst.2020.101906.

15. Melendez-Rodriguez, B.; Figueroa-Lopez, K.J.; Bernardos, A.; Martínez-Máñez, R.; Cabedo, L.; TorresGiner, S.; M. Lagaron, J. Electrospun Antimicrobial Films of Poly(3-hydroxybutyrate-co-3-hydroxyvalerate) Containing Eugenol Essential Oil Encapsulated in Mesoporous Silica Nanoparticles. Nanomaterials 2019, 9 , https://doi.org/10.3390/nano9020227.

16. Junmin Lai, Wu Lin, Peter Scholes, Mingzhong Li, Investigating the Effects of Loading Factors on the In Vitro Pharmaceutical Performance of Mesoporous Materials as Drug Carriers for Ibuprofen, Materials, 2017, 10, 150; https://doi.org/10.3390/ma10020150. 
17. Abidi, A.; Sebai, E.; Dhibi, M.; Alimi, D.; Rekik, M.; B’chir, F.; Maizels, R.M.; Akkari, H. Chemical analyses and anthelmintic effects of Artemisia campestris essential oil. Vet. Parasitol. 2018, 263, 59-65, https://doi.org/10.1016/j.vetpar.2018.10.003.

18. Aouadi, M.; Sebai, E.; Saratsis, A.; Kantzoura, V.; Saratsi, K.; Msaada, K.; Sotiraki, S.; Akkari, H. Essential oil of Rosmarinus officinalis induces in vitro anthelmintic and anticoccidial effects against Haemonchus contortus and Eimeria spp. in small ruminants. Vet. Med. (Praha) 2021, 66, 146-155, https://doi.org/10.17221/139/2020-VETMED.

19. Katiki, L.; Evangelista, A.; Canova, E.; Piza, A.; Fornazari, B.; Araujo, R.; Louvandini, H.; Amarante, A.; Costa, R.; Bueno, M. Anthelmintic activity of anethole, carvone, carvacrol, thymol, linalool, limonene, eucalyptol, vanillin, cinnamaldehyde and eugenol in in vitro tests. Planta Med. 2014, 80, P1L14, https://doi.org/10.1055/s-0034-1394672.

20. Popović, S.J.; Kostadinović, L.M.; Puvača, N.M.; Kokić, B.M.; Čabarkapa, I.S.; Đuragić, O.M. Potential of wormwood (Artemisia absinthium) as a feed supplement in rabbit diet: effect on controlling rabbit coccidiosis, antioxidative systems and growth performance. Veterinarski arhiv 2017, 87, 769-782, https://doi.org/10.24099/vet.arhiv.160704a.

21. Nigam, M.; Atanassova, M.; Mishra, A.P.; Pezzani, R.; Devkota, H.P.; Plygun, S.; Salehi, B.; Setzer, W.N.; Sharifi-Rad, J. Bioactive Compounds and Health Benefits of Artemisia Species. Nat. Prod. Commun. 2019, 14, 1934578X19850354, https://doi.org/10.1177/1934578X19850354. 